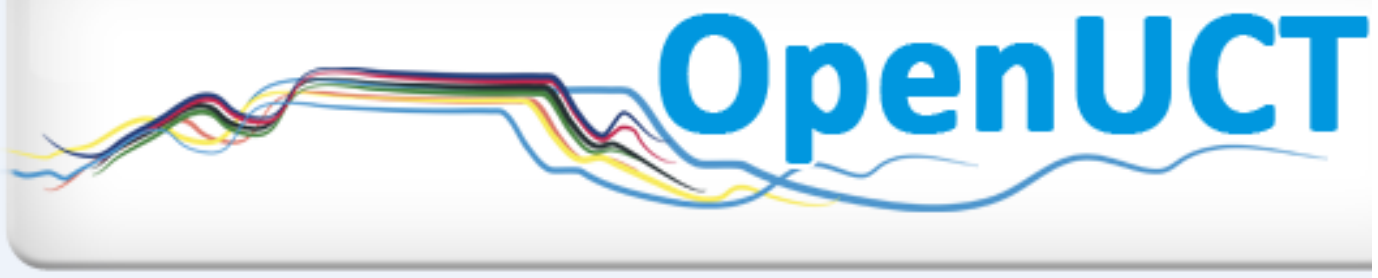

This is the post-print of Luckett, K. \& Hunma, A. 2014. Making gazes explicit: facilitating epistemic access in the Humanities. Higher Education. 67: 183-198. DOI: 10.1007/s10734-013-9651-7.

It is made available according to the terms of agreement between the author and the journal, and in accordance with UCT's open access policy available:

http://www.openuct.uct.ac.za/sites/default/files/UCTOpenAccessPolicy.pdf, for the purposes of research, teaching and private study. 


\title{
Making gazes explicit: facilitating epistemic access in the Humanities
}

Kathy Luckett • Aditi Hunma

\begin{abstract}
This paper addresses the problem of curriculum design in the Humanities and Social Sciences, and more specifically the challenge of designing foundation courses for first-generation or 'disadvantaged' learners. Located in the social realist school of the sociology of education studies that builds on the legacy of Basil Bernstein, we emphasise the importance of knowledge and understanding the principles that generate 'what counts' in particular courses and disciplines. In order to operationalise this, we used Maton's Legitimation Code Theory to uncover the knowledge/knower structures in eight first year courses in four of the most popular majors in a Faculty of Humanities. Our data sources were curriculum documents and exam papers in particular. The findings are presented and the 'codes', 'gazes' and 'lenses' for each set of courses delineated. The findings are being used to inform the design of a set of curriculum and pedagogic interventions that aim to offer powerful ways of knowing to novices in the Humanities and Social Sciences.
\end{abstract}

Keywords: Legitimation Code Theory, Bernstein, Sociology of education, Humanities, Curriculum studies, Higher education

\section{Introduction}

This paper is located in what has come to be known as the social realist school in the sociology of education that builds primarily on the legacy of Basil Bernstein (Young 2008; Moore 2009; Maton 2010). Writers in this school such as Muller, Moore, Maton and Young have called for a sociology of education that includes a theory of knowledge; that can account for the effects of knowledge codes on curriculum and pedagogy. Moore proposes a sociology of education that goes beyond a pre-occupation with the effects of structure and/or culture on educational outcomes to also account for the effects of 
knowledge (2009:8). The theory of knowledge proposed here is compatible with Bhaskar's (1979) critical realism: namely that one can both acknowledge that knowledge is socially produced and historically situated - and therefore always partial and fallible-and at the same time assert that knowledge is about an ontologically real world whose structure will affect what it is possible to know. This enables one to accept the relativity of knowledge but also to judge some forms of knowledge (powerful knowledge) as having greater explanatory power than others.

When applying the social realist approach to education located in contexts of social inequality, such as South Africa, this approach alerts one to the fallacy of conflating social hierarchies with hierarchies of knowledge. In South African post-apartheid policy and curriculum debates, this fallacy has led to attempts to validate indigenous knowledge and the everyday and/or workplace experience of subordinated groups in the formal curriculum. Social realists such as Muller have challenged this approach for ignoring the differentiated structure of knowledge. Following this line of reasoning, Maton and Muller (2007:17-18) pose the rhetorical question (para-phrased): do we change the curriculum to validate the 'code' (orientation to meaning) of the disadvantaged student, or do we give the student 'the key to the code' of the curriculum? This paper reports on a curriculum development project in the Humanities Faculty 1 at a research-intensive South African university that aims to respond to their challenge.

In South African universities, education levels of incoming school-leavers are highly uneven due to an impoverished and unequal state schooling system and affirmative action university policies necessary to redress past injustices through admissions policies. However, attempts to correct the unjust distributive logic of apartheid need to go beyond admission. Since the 1980s, various curriculum interventions, such as foundation courses in extended degrees, have been used in South African universities as mechanisms to 'catch up' the educational 'disadvantages' suffered by black students from poor schools and families. Such interventions have met with varying success. Foundation courses are often designed and taught by academic development practitioners who are not necessarily experts in the target disciplines. Many such courses focus on the development of academic skills or literacies in order to provide a generic platform from which students can proceed to first-year study in specific disciplines. Thus historically, at South African universities, foundation courses have tended to focus on skills development at the expense of contentwhich in some cases is regarded as an arbitrary vehicle for the teaching of academic skills or literacies. This leaves generic foundation courses open to attack from academics for ignoring content and more seriously, for having limited reach as a solution to the problem of academic 'under-preparedness'.

The position adopted here, following the social realist school, argues that in order to offer 'previously disadvantaged' students epistemic access to university study, one should attempt to design a curriculum that makes explicit the epistemic, recontextualising and evaluative logics (Maton 2013) of the pedagogic discourses to which they will be exposed. In the context of our practice-designing and running foundation courses in a Humanities Faculty-this means explicitly introducing students to the rules of disciplinary games in our courses, prior to their embarking on the first-year courses of their disciplinary majors.

The curriculum project reported on in this paper sets out to explicate the codes that prescribe and shape particular disciplinary identities, in other words, that 'specialise consciousness' (Bernstein 2001) in selected disciplines in the Humanities. The goal of the project is to design curricula for two new Humanities foundation courses titled 'Working 
with Texts in the Humanities' and 'Working with Concepts in the Social Sciences', that will make visible the underlying principles and hidden messages about what counts as legitimate academic performance in a range of Humanities courses. We asked the question:

Is it possible to offer disadvantaged students a platform of powerful knowledge in Foundation courses on which they can build when they begin their disciplinary majors?

The context for this research project is a traditionally liberal, elitist, research-intensive university that has a history of resistance to state interference and retains strong academic autonomy. In the Humanities Faculty, the disciplines remain the dominant organisational and structuring factor of the curriculum. Muller (2011) defines a discipline as a specialised, self-regulated domain of knowledge and practice. The fact that we are researching the curriculum at the start of the undergraduate curriculum means that there is greater likelihood of consensus on what should be taught and learnt than if we were working at the frontiers of research in the field of production (Bernstein 2000). However, the selection of content and pedagogic approach remains the prerogative of individual academics. This means that the task of making explicit and generalising about the 'rules of the game' in particular disciplines for students on foundation courses is a daunting task.

The challenge is compounded by the nature of the knowledges, or codes, in the Humanities. Bernstein (2000) characterised the Humanities and Social Sciences as having 'horizontal' knowledge structures (as opposed to the 'hierarchical' and more desirable structures of the Natural Sciences). He further suggested that knowing in the former is a matter of 'an acquired gaze'. Drawing on the works of both Bernstein and Bourdieu, Maton $(2000,2010,2013)$ in his Legitimation Code Theory has developed Bernstein's work on knowledge structures further, claiming that in the Humanities, implicit 'knower codes' (as opposed to more explicit 'knowledge codes') are dominant. One effect of the linguistic turn of the 1960s and 1970s has been to further complicate the Humanities field-new knower codes have been introduced that relativise and break with past epistemologies, carrying new gazes and more specialised dispositions (lenses) (Maton 2013). Thus knowers who have acquired particular dispositions or lenses may experience difficulty in reading and writing legitimate texts that are valued in other fields (Maton 2013). In this curriculum research and design project, we aimed to move beyond the genericism typical of many foundation courses and facilitate epistemic access by making the various gazes and lenses identified in large Humanities first-year courses more explicit. This paper presents the first phase of the project, where curriculum texts from four first year courses in Psychology, English, History and Film and Media are analysed and discussed. The findings are being used to inform the design of two new foundation courses for students entering the Faculty of Humanities.

\section{Conceptual framework and method}

Our data sources for this project are all curriculum documents i.e. examples of 'pedagogic discourse' (Bernstein 2000). With the permission of course convenors and Heads of Departments, we collected course outlines, course guides, exam papers and samples of student scripts from first year courses in the highly subscribed majors in the Humanities faculty for two consecutive years, 2011 and 2012. In this paper, we report on our analyses of the pedagogic discourses of four of the most popular Humanities disciplines-Psychology (PSY), English Language and Literature (ELL), Historical Studies (HST) and Film and Media (FAM).2

\footnotetext{
${ }^{2}$ The analyses are work-in-progress and currently exclude student scripts-which will be used to triangulate our data analysis in the next phase of the project.
} 
As suggested above, our theoretical focus is on delineating 'relations within' knowledge and educational practices as opposed to earlier preoccupations of the sociology of education with 'relations without', that is, with how social power distorts knowledge. To do this, we applied to selected Humanities disciplines one dimension of Maton's $(2010,2013)$ Legitimation Code Theory (LCT) — specialisation—where Bernstein's concepts of classification and framing are used to surface what counts, what is valued or worthy of distinction and what is recognised as specialised practice. Maton (2010) describes one dimension of the 'relations within' knowledge as the epistemic relations (ERs) and social relations (SRs) that specialise knowledge practices. Epistemic relations are between knowledge practices and their objects, and their principles and procedures, (what can be known and how it is known); while the social relations are between knowledge practices and their subjects or actors. Each can be more strongly $(+)$ or weakly $(-)$ emphasised as the basis of achievement, giving a range of 'specialisation codes' (ER, $\pm S R \pm$ ). These include:

- knowledge codes (ER $\mathrm{R}_{+}$, SR-) where specialised knowledge of specific objects of study is emphasised as the basis of achievement, and the attributes of actors are downplayed (such as conventional portrayals of Mathematics and the Natural Sciences); and

- knower codes (ER-, SR $_{+}$, where specialised knowledge and objects are less significant and instead the attributes of actors are emphasised as measures of achievement, such as notions of 'natural genius', 'cultivated taste' or standpoint theories based on class, race and gender.

'There are also two further specialisation codes: elite codes, where both specialist knowledge and knower dispositions are emphasised; and relativist codes, where neither matter. We shall focus on knowledge codes and knower codes, which we shall show help reveal the organising principles of Psychology (knowledge code) and English Language and Literature, Historical Studies and Film and Media (knower codes).

By analysing specialisation codes, one set of the organising principles underlying educational achievement can be revealed. These concepts have been widely used to explore a range of educational practices and contexts, (Lamont and Maton 2008; Luckett 2009; Shay 2011). However, for our study we needed further means for distinguishing among the knower codes of English, Film and Media, and History. To explore their 'rules of the game' we draw on a second level of analytical delicacy offered by Maton (2013: 82-101, 182-90), which reveals different kinds of knower codes. Maton distinguishes two kinds of social relations: subjective relations (SubR) between knowledge practices and 'kinds of knowers', such as the social category of the knower; and interactional relations (IR) between knowledge practices and 'ways of knowing', such as particular relationships with significant others, e.g. apprenticeship with a master. These may be stronger (+) or weaker (-) and, just as with the codes, varying their strengths generates four principal modalities or 'gazes':

1. a cultivated gaze weakly bounds and controls legitimate categories of knower but strongly bounds and controls legitimate interactions with significant others (SubR-, IR+), often involving acquiring a 'feel' for practices through, for example sustained exposure to exemplary models or prolonged apprenticeship under an acknowledged master;

2. a social gaze relatively strongly bounds and controls the kinds of knowers who can claim legitimacy (such as standpoint theories based on class or gender) but relatively weakly constrains their ways of knowing (SubR+, IR-); 
3. a born gaze strongly bounds and controls both legitimate kinds of knowers and legitimate ways of knowing (SubR+, IR+);

4. a trained gaze weakly bounds and controls both legitimate kinds of knowers and legitimate ways of knowing (SubR-, IR-), so here social relations are relatively weak.

This provides a sharper understanding of the 'rules of the game' of different knowledge practices. As we shall show, the courses we focused on in English Language and Literature, Film and Media, and Historical Studies represented knower codes with cultivated gazes. To make explicit to students their organising principles we drew on a third level of analytic delicacy within specialisation codes: the notion of 'lenses'. Maton (2013:

182-190) describes how the basis of cultivating knowers into a legitimate gaze may differ and highlights two 'lenses': an 'ontic lens' of an object of study and a 'discursive lens' of intellectual studies of that object. For example, the basis of cultivation may be great works of art or culture (an ontic lens) or it may be theories and studies of art or culture (a discursive lens), such as the difference between being immersed in exemplary models of literature or of literary criticism, and events in History or historiography (Fig. 1).

Unlike the knowledge codes, where the epistemic relations are to real-world empirical objects, we found that in many Humanities discourses, 'the what' is a canonical or privileged text that stands in the place of a real-world referent, but none-the-less is a required reference with which legitimate knowers must engage. Thus we tried to ascertain how strongly the pedagogic discourses bound and control the textual referents to be studied from within the literary canon (or discursively constructed 'facts' in the case of Historical Studies). In the Humanities especially, it would appear that texts not only mediate between the knower and the real world, they are understood to transform what counts as real. Texts may even supersede that of which they are re-presentations to generate what Baudrillard (1994) would call 'hyperreality'. In fact, post 'the linguistic turn', significant canonical texts have become the referents of the discourse, imbued with an ontological status in which they are understood to de- and re-construct (social) reality. They have become the knowers' new reference point and their engagement with these can be viewed as more meaningful than the quest for empirical truth. Hence, we were particularly sensitive to the use of texts as denominators of the 'what' and 'how' of interactional relations, especially in the case of the cultivated gaze (Fig. 2).

Using the concepts from specialisation outlined above, we developed an external language of description (a coding instrument) to analyse the curriculum texts, using the following choice range (degrees of classification and framing): - -/-/+/++. Each cell in the table is set up as a node in NVivo and coded clauses or phrases from the curriculum texts are categorised and stored accordingly (see Appendix, Table 2). As the project proceeds, this will allow for on-going and deeper analyses. Once analysed, we summarised our findings by plotting the different courses on a Cartesian plane using SubR and IR axes to capture the different gazes for knower codes. (see Appendix Fig. 3).

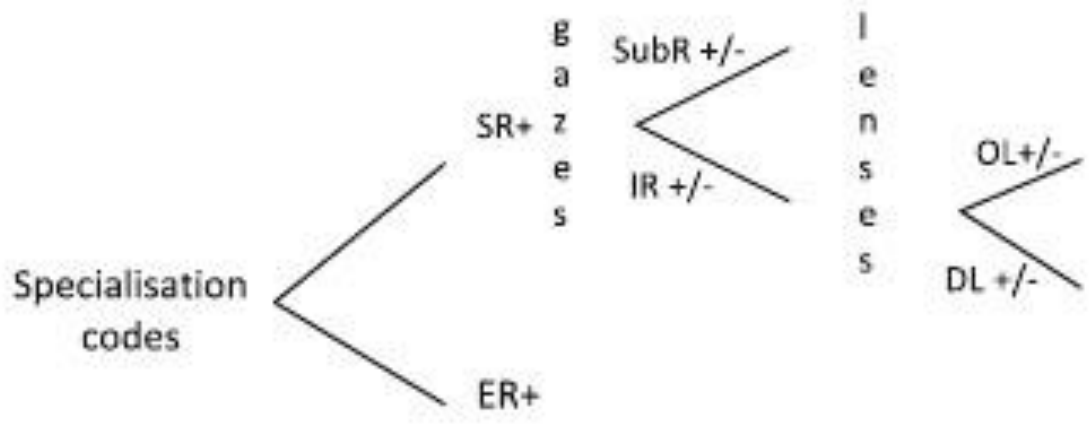

Fig. 1 Specialisation codes (based on Maton 2013) 


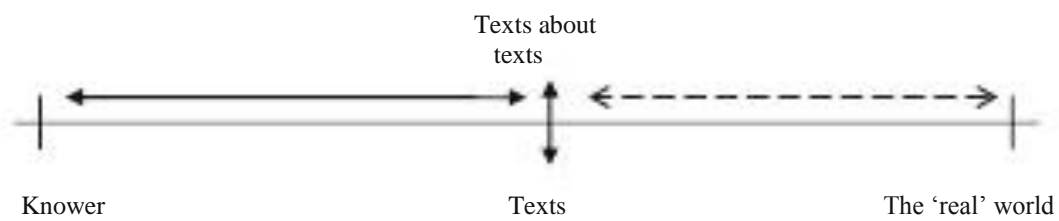

Fig. 2 Text mediation

\section{Findings}

Here we offer a summary of our data analysis of curriculum texts (pedagogic discourses) from the first year courses of the four selected disciplines.

\section{Psychology (PSY1004F \& PSY1005S)}

The Introduction to Psychology Part 1 (PSY1004F) defines Psychology as the 'scientific study' of the experience, behaviour and mental processes of individual persons. It explains to students that Psychology attempts to explain natural but non-material reality and that the unit of analysis is the individual. The emphasis of the first year courses is on behaviourist and cognitive psychology (with no mention of psychoanalysis or the socio-cultural perspective). This is explained by the fact that these courses are compulsory 'service courses' for students in the Faculty of Health Sciences' Health and Rehabilitation Sciences. Clearly, the two courses align themselves with the Sciences where epistemic relations are dominant (in Maton's terms, a knowledge code). The course outline suggests that both propositional knowledge (knowing that) and skills (knowing how) will be the focus of this course,

We intend not only to look at the contents or material of Psychology, but also to help you develop skills to make a critical evaluation of what you read.

The tutorials claim to focus on the development of skills. On closer inspection, tutorial questions start off by requiring answers to a set of 'what' questions, for example 'What is an independent variable?' 'What is a dependent variable?' and 'What does it mean to vary an IV and measure a DV?'-suggesting a strong framing of factual information. The questions then shift gear to 'how-type' questions, for example, 'How does one operationally define a variable?' 'How would you structure a research report for you research idea?' Other tutorial questions typically follow this format: they require students to know specific facts or concepts such as personality traits, memory, operant learning, depression, and then to apply these to particular cases or scenarios. Typically, students are expected to provide correct diagnoses for the symptoms described in the cases.

How students are to do this remains implicit, but the model answers and the use of MCQs in the exams suggest that there is one preferred diagnosis, application or procedure. The strong framing of explicit procedures and research methods suggests a strong focus on getting the procedures right. This is confirmed in the second semester course that requires students to conduct and report on a correlational or experimental study (using a very specific experimental or quasi-experimental research design and basic descriptive statistics). The use of 'scientific, rigorous and systematic' research methods is strongly framed (PSY1005S Course Handbook 2012, p. 7).

The exam papers are divided into two sections. The first section contains a choice of short answer questions that require students to apply concepts and theories correctly to 
particular cases or scenarios. These questions require students to define, describe, illustrate and also to discuss, for example:

Memory involves one area of the brain only. To what extent do you agree with this statement? Draw on the case of HM to illustrate your answer.

Students need to be well-versed in the facts as well as text-book cases and examples, legitimating their performance through an accurate knowledge of facts and empirical applications, as well as demonstrating appropriate reasoning processes. The second section of the exam papers contains multiple-choice questions. Most items are recall questions starting with 'What'. There are also some 'fill in the blanks' statements. What is valued here is knowledge of the course content. Other multiple-choice questions attempt to stretch students' thinking by giving them a scenario and asking them to provide the answer that best fits the case (application of correct knowledge). The basis for legitimation remains knowing facts and concepts and the ability to apply these correctly to real world cases. For example,

For various reasons I am in trouble with the Economics Department. Whenever I start working on one of their essay assignments [...]. The ritualistic behaviour sequence detailed above is most probably sustained by:
a. Response generalisation
b. Positive reinforcement
c. Negative reinforcement
d. Punishment

Overall, we concluded that knowledge in the first-year Psychology courses is legitimated on the basis of strong epistemic relations to the real world located in an empiricist paradigm. The basis for legitimation is a knowledge code (ER), that is, knowing that and how, with additional requirements for some interpretation and clinical reasoning. We found that when first year students are taught research methods, as in the second semester course, the procedural requirements are also strongly framed, to scaffold the development of a rigorous approach to research. Furthermore, the constant allusions to 'cases' and the requirement to apply strongly framed facts and concepts to particular real-world examples, suggests that procedural knowledge about how to apply this knowledge is also valued. We thus coded the Psychology courses (in these courses predominantly behaviourist and cognitive Psychology) as knowledge codes. We suspect that this knowledge code clashes with the knower codes cultivated by the majority of Humanities disciplines.

\section{English Language and Literature (ELL1013F \& ELL1016S)}

The first year English courses aim primarily to familiarise students with 'literary and rhetorical terms' and 'basic issues in literary studies'. The first semester course introduces students to different literary genres and types of 'critical writing' with a view to helping them 'hone their own writing skills'. The second semester course builds on the skills taught in the first semester and looks more specifically at literary issues in the post-colonial context. The course outlines suggest an emphasis on teaching the concepts of textual analysis and on how to engage with canonical texts. In the Tutors' Handbook, the English Department states its expectations that tutors will 'become experts on the set texts' and 'foster critical literacy'. However, tutors are also told that 'teaching is of course a very personal thing-some tutors prefer to be left to their own devices; others appreciate more support and scaffolding'. Furthermore, tutors are instructed to 'encourage debate, dissent and disagreement' on 
particular topics, indicating strong a framing of subjective relations. The essay writing guidelines are expressed as follows:

Essay writing is a complex process. There are tensions in that: on the one hand, students are required to show expression of independent mind, whilst on the other, they have to follow a code of accepted academic practice.

Thus, students' work is expected to be 'original' while also showing evidence of 'extensive reading' of others' work and following the appropriate conventions of academic register and referencing.

The first semester exam papers show apparent weak framing, but we suggest that this may be deceptive; students are free only to demonstrate that they are certain kinds of knowers. For example, in one question students are given leeway to modify the title, while in the poetry question they can choose between two given poems-but are nonetheless given strict instructions on how to proceed:

You must refer to the text of the poem to support or illustrate all your thoughts. Do not summarise the content of the poem.

Another question asks students to respond to a selected passage from 'Heart of Darkness':

How does Conrad's 'Heart of Darkness' challenge readers to think again about the nature of language and representation? Your essay should be well structured and should include a detailed analysis of the passage above. Avoid simply retelling the story.

Here the specific text is strongly framed. The knower is expected to demonstrate a 'cultivated gaze', to engage in a meta-discourse about language and representation and know how to produce a 'well-structured essay'.

Second semester exam questions require students to engage with the texts of significant others about selected texts. For example students are asked to read a quote by Virginia Woolf who is presented as being 'impatient with Forster's work'. The question asks:

With close reference to the language, structure and narrative methods of 'A Passage to India', explore why Woolf might have come to this verdict. To what extent do you agree or disagree with her?

Here students are expected to show knowledge of literary devices, structure and particular narrative methods employed in the novel, to assess the effects of those devices on the pace of the novel and to reflect on these in light of Woolf's comments. The second part of the question is more discursive requiring students to take a stand and provide reasons why they would agree or disagree with Woolf.

Another question asks students to analyse an excerpt from 'On Beauty' and asks a series of questions on the text. Most of the tasks require students to link the text to broader themes in the novel such as 'cultural hybridity', 'multiculturalism', 'race' and 'class'. The tasks make four kinds of demand on the students. They require a detailed knowledge of the novel as a whole, skills to analyse the excerpt at hand, knowledge of broader literary studies themes and ways of linking aspects of the novel to these themes.

In the Tutor's Handbook, the Department refrains from prescribing a strict marking rubric, explaining that:

It would be wrong to represent the Department as having dogmatic positions. There can be no simple formula that deducts a set number of marks for each error of fact or syntax. This is why the opinion of two markers is necessary to establish a mark... 
It would be misguided to interpret this as an example of dithering about what knowledge is required. Rather, we suggest that this is an example of what Maton (2010) calls the 'knower grammar', which typically applies to Liberal Arts disciplines. Instead of precise and replicable descriptions of what is required, it presents the values, principles and dispositions that form the basis of a hierarchical knower structure. In line with those values, the Department refrains from giving examples of excellent or good essays, but rather states, 'To achieve such high marks the argument should be original and worthy of publication; the prose should be grammatically flawless and stylish' (Tutors' Handbook, p. 24). In this, it firstly assumes that the tutors are already sufficiently socialised into the discipline to identify essays of such calibre. Secondly, by not setting the standards explicitly, it insists on remaining open to the agential potential of 'talented' but wellsocialised knowers who may produce essays that exceed expectations and outshine former students.

Overall, our analysis suggests that English is a knower code and that in these first year courses the knower is framed as 'cultivated'; the interactional relations and practices for engaging with canonical texts are strongly framed. Furthermore, as the course proceeds, the knower is expected to engage with the texts of significant others about the texts in question. Subjective relations are relatively weakly classified and framed-direct prescriptions about the identity and performance of the knower are avoided-there appears to be a deliberate stepping back from this, in the hope that knowers might express themselves in novel and creative ways. We suspect that this apparent weak framing is underpinned by a particular knower disposition. In sum, the basis for the legitimation of knowers in these courses relies primarily on how they engage with canonical texts (cultivated gaze, ontic lens) and in more demanding cases, how they engage with the texts of significant others about these canonical texts (cultivated gaze, discursive lens).

Historical Studies (HST1004F, HST1005F, HST1010S)

The History Guidebook for students prepared by the Department of Historical Studies describes the knowledge in which it deals thus,

History at university level is not just about facts. While the past does not change, our interpretations and understanding of it certainly has. The different ways historians have written about history is called historiography. As you will see in many courses, history and economic history often deal with contested interpretations of the past. $(\ldots)$ it is important that as an academic reader you process the argument and the evidence provided in each reading. (p. 7)

At its core, History focuses on knowing and explaining content, context, causal relationships, continuity and change. (p. 11)

In tackling a historical text, students are urged to ask themselves the following kinds of questions:

What is the author's basic argument? Do I agree with it?

What is this author's perspective or position?

How does the author use evidence to support their claim?

Are there some facts that have been left out or misinterpreted?

Does the author's conclusion seem logical and well supported? (p. 9) 
The course is designed to introduce you to a variety of historical topics from around the world at the same time as introducing you to different ways of writing about and appreciating history.

The course aims are stated as firstly to 'consider key themes in the history of the emergence of a global consciousness'-large sweeps of highly abstracted and condensed information across time and place-and secondly to 'consider the different ways in which historian approach the past.' This confirms the requirement for knowers to master both evidence and interpretation.

These extracts suggest that History students are required to be knowers with a cultivated gaze that involves the cultivation of both knowledge of historical facts or evidence (an ontic lens), as well as engaging with historians' interpretations of those facts and ways of constructing arguments (a discursive lens). What makes historical studies complex, especially for first-years, is that behind concepts such as 'evidence' there is a subordinated epistemic relation (ER-) assumed by History's implicit empirical method. This is supported by tips in the Guidebook such as 'you are expected to show accurate knowledge of the material that is relevant to a particular topic.' Students are told to build an argument using 'available evidence (facts) as well as the ideas and interpretations suggested by other writers whose works you would have read in preparation for your essay' (p. 10). However, the extract that follows which explains historiography, suggests that even the 'facts' are to be understood as interpreted, confirming a knower code,

History, especially at university level, often involves dealing with conflicting evidence and differing interpretations. Often, historians disagree with each other about how to interpret the past. Understanding how historians have written history is called historiography. Most of the questions you will encounter in history will require you to acknowledge and discuss arguments or evidence that contradict your chosen argument or approach. (p. 12)

The Historical Studies first-year exam papers require students to know and select relevant 'facts', engage critically with the knowledge claims of historical accounts and of significant historians and understand the contexts from which both primary and secondary sources were written. Here are some examples,

What was the significance of the frontier in American history, according to Frederick Jackson Turner? What criticisms have been made of his arguments? (HST1010S 2012)

Do you agree with Benjamin Madley that the destruction of Yuki society was a clear case of genocide in terms of the definition set out in the United Nations Convention on genocide? (HST1010S 2012)

This question from Economic History suggests that students need to know factual information about the period as well engage with the discourses about macro-economic policy of the time,

What was the response of Ronal Regan and Margaret Thatcher to the economic downturn at the end of the 1970s? How did this differ from the Keynesian consensus? (HST1005F 2011)

These questions demand high levels of discursive competence and historiographical understanding, 
What do you understand by the term 'cultural imperialism' and do you agree with Kwame Anthony Appiah that its negative effects have been exaggerated?

(HST1004F 2011)

How useful is the concept of 'invented tradition' to the historian of nationalisms in twentieth-century South Africa? (HST1010S 2012)

'Indian captivity narratives not only tell us about American identity but also about Indian culture, Englishness and the shaping of a wider British imperialism'. To what extent do you agree with the above statement? Provide evidence to support you answer. (HST1010S 2012)

\section{The Departmental marking scale describes a $90 \%$ ? essay as}

An outstanding answer, worthy of a postgraduate student and showing mastery of historical method. Gave your marker new insight into the topic. (p. 20)

An essay worth $80-85 \%$ essay is described as

Very well argued and substantiated with many original ideas; nuanced and makes appropriate and insightful use of new material. Elegantly expressed. (p. 20)

These descriptions suggest a strong knower code in which the 'historical method' to be mastered remains implicit. We suggest that the basis for legitimacy in these courses is a knower whose identity is neither prescribed nor made explicit, but who knows how to carry out the desired practices - namely how to write an argument that is rhetorically elegant, supported by evidence and which also engages critically with the interpretations of other historians or significant knowers: knower code: cultivated gaze: both ontic and discursive lenses.

\section{Film and Media (FAM1001F \& FAM1000S)}

The first semester introductory course 'Media and Society' focuses on 'the importance of mass media in modern society and questions the roles that the media play in public life' as stated in the course outline. The material introduced is initially concrete and specific to the South African context and seems to favour strong subjective relations drawing on students' own experiences with the media. However, when triangulated with data from the exam paper, this relation is often subordinated in practice.

Initially, students are given simple editing exercises where they need to exercise a trained proofreading gaze.

Write down the CORRECT version of the underlined words in each of the following sentences: [5 marks]

1. I need to license/licence my vehicle.

2. The drugs seem to have no affect/effect on her.

3. There are less/fewer than twenty women in the group (Exam paper, 2011).

Here, the examiners expect a single correct answer, which does not depend on students' ability to forge subjective relations. This section of the exam also contains questions requiring students to define key terms, i.e. 'what' questions that test students' recall rather than reasoning ability thus featuring low in the social relations hierarchy.

However, the questions that follow suggest a knower code with strongly framed interactional relations. In some cases students are also expected to be well-acquainted with the prescribed texts. For example: 
Use Roland Barthes's analysis of the young African soldier on the cover of Paris Match to explain why he argues that images have an ideological function. Now suggest, using Stuart Hall's terms, what a dominant, negotiated and resistant reading of that image might be. [10 marks]

Here, students first need to show that they know the content of the canonical 'Paris Match' cover (ontic lens), then show that they understand Barthes's analysis and can justify his argument for the ideological function of images. They also need apply Hall's concepts in order to generate alternative readings of the image (discursive lens).

Subsequent questions are more procedural and strongly framed; students are given clear guidelines about how to proceed in analysing prescribed texts, for example:

Write an essay in which you provide a full semiotic analysis, in 3-4 pages, of the April 2011 Getaway magazine cover attached. (Note: the green 'travel bug' over the letter e on the cover is linked to a competition on the Getaway website.) In your analysis, you should try to cover the following:

- Denotation and connotation

- The various kinds of signs on the cover

- Visual codes and visual elements such as typography and the positioning of characters and the viewer

- The implied narrative of the cover

- The suggested audience for the magazine

- Whether the cover carries any kind of ideological message about what travel should be.

The question also requires students to pay close attention to the text and demonstrate, through the detailed analysis, their familiarity with it (cultivated gaze, ontic and discursive lens).

The final question in this section again privileges a discursive lens. Students are expected to 'critically discuss the relationship between media, ideology and hegemony' while referring to the documentary 'Manufacturing Consent' (screened in class) 'and other literature in this course'. While the question appears to give students more freedom to explore the links between the concepts 'media', 'ideology' and 'hegemony'-they can draw from a variety of texts and theories to support their claims, one suspects that there is a certain way of answering the question. By limiting students to the prescribed readings, the examiners narrow down the scope for students to express their subjective responses. Thus the course inducts students into particular procedures and ways of interacting with texts and media. It introduces them to certain semiotic concepts to 'interrogate the relationship between audiences, media texts, technology and society', and 'a diverse range of writing styles' (cultivated gaze, ontic and discursive lens).

The second semester course 'Analysing Film and Television' seems to build on the first semester not only offering 'a critical engagement with film and television' but also an opportunity to apply the semiotic tools acquired thus far to strongly framed set visual texts. The course is described as follows:

It is one of the few courses in which you can legitimately call going to the cinema and watching TV research.

However, the promise of strong subjective relations is not fully realised. Instead, the course extends students' repertoire of existing semiotic tools and teaches them the 'language of screen texts and the anatomy of visual storytelling' (discursive lens). A writing component is built into the design and students are given the opportunity to 'put [their] understanding 
of narrative structure, genre, and the elements of visual storytelling into practice by demonstrating how [they] would adapt a prescribed passage of literature into either a storyboard or script', suggesting a cultivated gaze.

The November exam for this course makes a relatively greater demand on students' knowledge about textual analysis, suggesting a more trained type of gaze.

What is the difference between a dissolve and a wipe? Describe two instances where a director might make use of a wipe in a film.

However, the second part of each question is more weakly framed and students are asked to provide their own examples to illustrate the concepts specified for working with discourses.

In section $B$, the questions appear to require a knowledge of selected texts (ontic lens) as well as knowing how to engage with them (discursive lens). For example:

With reference to specific scenes in Legally Blonde, discuss how the film's mise-enscene contributes to the affirming and questioning of cultural stereotypes.

On the whole, the exam papers for FAM suggest a strengthening of the interactional relations as students move from the first to the second semester. The early work at the beginning of the year requires a trained gaze, but this soon shifts to a cultivated gaze.

Thus, our analysis of the curriculum texts for the two first year FAM courses suggests a strong emphasis on interactional practices and procedures for working with texts and discourses. Despite a stated desire to allow students' subjective responses to texts, we suggest that these are in fact subordinated to the strongly framed requirements to adopt a certain procedural gaze for analysing texts.

\section{Discussion and conclusions}

In this section, we discuss the practical and theoretical significance of our analysis. We now have a grasp on what kinds of symbolic structures and meanings are possible and privileged in certain Humanities disciplines, as manifested in particular first-year courses-but what does this mean for designing and teaching a foundation course? To re-cap: We embarked on the project with the aim of making more explicit the hidden dispositions and orientations to meaning assumed by certain knower codes. Building on Bernstein, we used Maton's Legitimation Code Theory to surface the principles that underlie and generate these codes and their distinctions. We did this by analysing data collected from the pedagogic discourses of selected Humanities courses with a focus on surfacing 'what counts' in the exam papers. On the basis of our findings we inferred the knowledge/knower codes (gazes and lenses), the intrinsic properties or 'internal relations' of the different kinds of disciplinary knowledge from which the curricula for the target first-year courses are derived. With the exception of the Psychology courses, which we identified as dealing with a knowledge code, the other three sets of courses were identified as cultivated knower codes. Following Maton (2010, 2013), this suggests that successful performance in these courses is based on knower attributes, dispositions and an ability to carry out certain intellectual practices in particular ways. These attributes are usually cultivated through prolonged apprenticeship and immersion in exemplary models under the tutelage of disciplinary masters. Importantly, in cultivated knower codes, these practices are in principle open to any learner who is able to acquire the gaze.

It is worth noting that, in disciplines underpinned by tacit knower codes-and in higher education where researchers and lecturers are usually the same people-the analysis of 
curricula that academics design can give one access to their assumptions about the basis of legitimation in their field. 3 Our task is now to translate our findings back into a new set of Humanities foundation courses that will deliberately articulate and model the relations, practices and dispositions seen to be valued in the target first-year courses. While acknowledging that one can neither simply read off a curriculum from a knowledge structure, nor easily unravel the epistemic from the social or the necessary from the arbitrary (these are only analytic distinctions), we believe that through our analysis, we have begun to make visible the different types of gazes and lenses that must be acquired to succeed in a range of Humanities knower codes (and one knowledge code).

The pedagogic challenge for the Humanities foundation courses thus becomes how to talk explicitly about what is valued, how to demonstrate the interactional practices and model the gazes and lenses identified so that students acquire the rules of the game, learn to produce legitimate texts and display the right kind of knower attributes and dispositions, a 'specialised consciousness'. One way to do this is to talk about the disciplines, the history of their development, their foci (the what) and the demands of their practices (the how). A better approach is to model the practices and to scaffold students' acquisition of these; but the latter takes time and immersion, which are labour-intensive and expensive for a developing country's expanding higher education system. The foundation courses have been designed to do both, that is work at both the explicit and implicit levels of acquisition. With regard to the latter, with the help of disciplinary course convenors, we have carefully selected texts to work on with the students. These texts are understood as realisations of specific meaning-making systems and symbolic structures. The challenge is to unpack the texts in the classroom in such a way that the micro-practices of their lexico-grammars, genres and other discursive features (field, tenor and mode) can be linked to their contexts of production. 4 With practice, it is hoped that students will begin to become the right kinds of knowers and acquire the desired cultivated gazes - for example, learn how to think, read and write like historians, literary critics or media practitioners and demonstrate this by producing legitimate written texts. A further practical implication is based on the distinction of the Psychology courses as knowledge codes. At a policy level, in order to avoid confusing students with a 'code clash' in their foundation year, we have proposed that a separate foundation course for Psychology be developed. This would enable students to focus on learning the propositional and procedural knowledge demanded by that discipline, as opposed to the cultivating particular gazes for the knower codes.

We recognise that going forward into their majors, students will have to manage epistemological upheavals and on-going contestation, fragmentation and segmentation in the Humanities and Social Sciences. By teaching students at foundational level that every Humanities discourse has a particular gaze (and lens), and by teaching them how to identify this through the methods of close textual analysis, we hope that they may develop the know-how to crack any new knower codes that they encounter.5

This paper reports on work-in-progress. Curriculum documents from other Social Science target courses are currently being analysed, as are student scripts. The impact of the new foundation courses will be evaluated by monitoring students' performance in the

\footnotetext{
${ }^{3}$ Albeit acknowledging Bernstein's insistence on a 'discursive gap' between the Field of Production (research) and the Field of Recontextualisation (curriculum) (Bernstein 2000).

${ }^{4}$ The best methods we have found that are compatible with the social realist approach are those of the Sydney school of functional linguistics (e.g. Martin and Rose 2003).

${ }^{5}$ The imposition of knower codes that require particular dispositions and subjectivities in a post-colonial context is a topic for another paper.
} 
target first-year courses. If proved effective, we hope that this approach will have some influence on the curriculum and pedagogy of mainstream first-year courses; but at this stage, the effectiveness of this approach in providing 'epistemic access' to 'disadvantaged' students is yet to be demonstrated.

Acknowledgments We would like to thank Karl Maton from the University of Sydney for his informal feedback in a conference presentation on which this article is based.

\section{Appendix}

See Tables 1, 2 and Fig. 3.

Table 1 Showing the patterns that emerged from the data analysis

ELL courses

PSY courses

HST courses

FAM courses

$\mathrm{SR}+$

SubR

$\mathrm{IR}$

IR+

OL

DL

ER+

$$
+
$$

$++$

$+$

Table 2 NVivo nodes for humanities knowledge and curriculum project

$\begin{array}{llllllll}\text { ER } & \text { ER } & \text { ER } & \text { ER } & \text { SR } & \text { SR } & \text { SR } & \text { SR } \\ ++ & + & - & -- & ++ & + & - & --\end{array}$

\section{Knower code}

SR?

Gazes Coding

Born SubR+, IR+

Cultivated

SubR-, IR+

(X)

Social

SubR+, IR-

(X)

Trained

SubR-, IR-

(X)

(X) X

Cultivated gaze

Lenses

Coding

$\mathrm{OL}+, \mathrm{DL}+$

(X)

Discursive

OL-, DL+

Ontic

$\mathrm{OL}+$, DL-

OL-, DL-

(X)

(X)

$X$

$x$

X

Knowledge code

ER

$\begin{array}{lll}\text { Insights } & \text { Coding } & \\ \text { Purist } & \text { OR+, DR+ } & \text { X } \\ \text { Doctrinal } & \text { OR-, DR+ } & \\ \text { Situational } & \text { OR+, DR- } & \text { X } \\ \text { Relativist } & \text { OR-, DR- } & \text { X }\end{array}$

Relativist OR-, DR-

(X)

(X)

X $(X)$ 


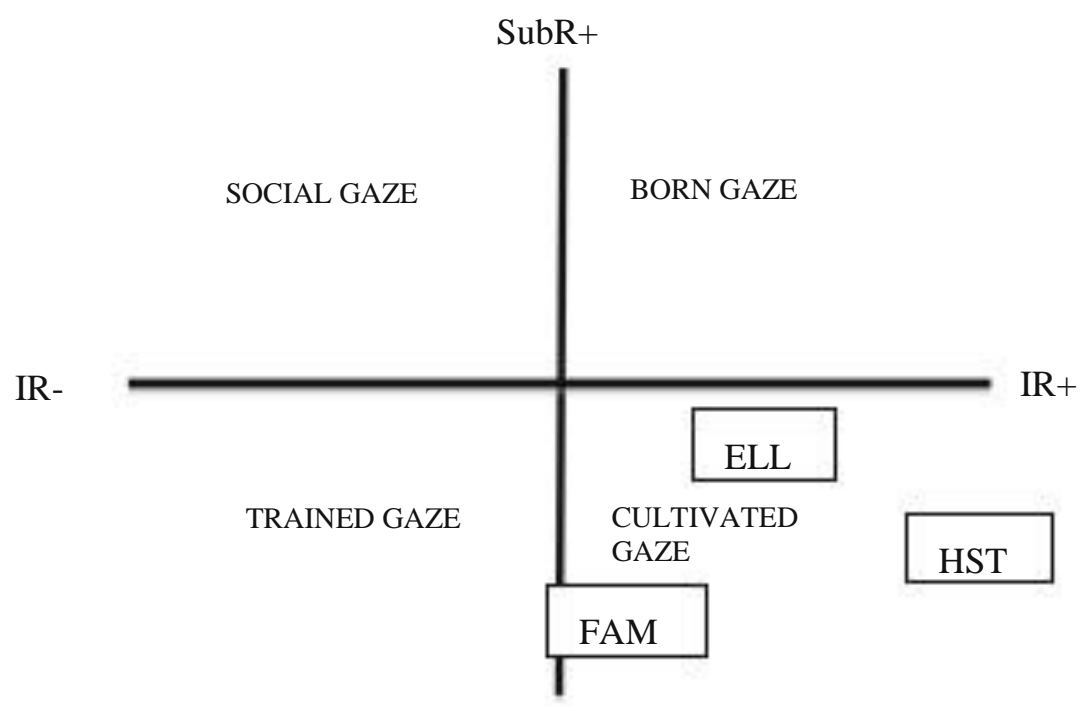

SubR-

Fig. 3 Knower codes: social relations, cultivated gazes

\section{References}

Baudrillard, J. (1994). Simulacra and simulation. Ann Arbor: University of Michigan Press.

Bernstein, B. B. (2000). Pedagogy, Symbolic control and ldentity: Theory, Research, Critique (Revised ed.). Lanham: Rowman \& Littlefield Publishers, Inc., Chapter 1: Pedagogic codes and their modalities of practice, pp. 3-24.

Bernstein, B. (2001). From pedagogies to knowledges. In A. Morais, I. Neves, B. Davies, \& H. Daniels (Eds.), Towards a sociology of pedagogy: The contribution of Basil Bernstein to research (pp. 363-384). New York: Peter Lang.

Bhaskar, R. (1979). The possibility of naturalism: A philosophical critique of the contemporary human sciences. New Jersey: Humanities Press, Inc.

English Department (2012). Tutors' Handbook. Cape Town: University of Cape Town Press (unpublished). History Department (2012). History Guidebook. Cape Town: University of Cape Town Press (unpublished).

Lamont, A., \& Maton, K. (2008). Choosing music: Exploratory studies into the low uptake of music GCSE. British Journal of Music Education, 25(3), 267-282.

Luckett, K. (2009). The relationship between knowledge structure and curriculum: A case study in sociology. Studies in Higher Education, 34(4), 441-453.

Martin, J., \& Rose, D. (2003). Working with discourse: Meaning beyond the clause. London: Equinox.

Maton, K. (2000). Languages of Legitimation: The structuring significance for intellectual fields of strategic knowledge claims. British Journal of Sociology of Education, 21, 147-167.

Maton, K. (2010). Progress and canons in the arts and humanities: Knowers and gazes. In K. Maton \& R. Moore (Eds.), Social realism, knowledge and the sociology of education: Coalitions of the mind. London: Continuum.

Maton, K. (2013). Knowledge and knowers: Towards a realist sociology of education. London: Routledge.

Maton, K., \& Muller, J. (2007). A sociology for the transmission of knowledges. In F. Christie \& J. Martin (Eds.), Languages, knowledge and pedagogy: Functional linguistics and sociological perspectives (pp. 14-33). London: Continuum.

Moore, R. (2009). Toward the sociology of truth. London: Continuum.

Muller, J. (2011). Through other's eyes: The fate of the disciplines. In F. Christie \& K. Maton (Eds.), Disciplinarity: Functional linguistics and sociological perspectives (pp. 13-34). London: Continuum.

Psychology Department (2012). PSY 1005S Psychology Handbook. Cape Town: University of Cape Town Press (unpublished).

Shay, S. (2011). Curriculum formation: A case study from History. Studies in Higher Education, 36(3), 315-329.

Young, M. (2008). From constructivism to realism in the sociology of the curriculum. Review of Research in Education, 32(1), 1-28. 